\title{
Individual and Combined Effects of PNF Stretching and Plyometric Training on Muscular Power and Flexibility for Volleyball Players
}

\author{
Efectos individuales y combinados del estiramiento y entrenamiento pliométrico sobre potencia \\ muscular y flexibilidad para jugadores de voleibol
}

Received: October 23, 2020
Accepted: December 19, 2020

\author{
Written by: \\ Amr H. Tammam ${ }^{15}$ \\ https://orcid.org/0000-0003-1664-6423 \\ Enas M. Hashem ${ }^{16}$ \\ https://orcid.org/0000-0001-9544-9123
}

\section{Resumen}

El conocimiento adquirido a través de este estudio podría ayudar a que el entrenamiento pliométrico sea más efectivo cuando el estiramiento de Facilitación Neuromuscular Propioceptiva (FNP) se agregue a los entrenamientos sin tener que aislar la fuerza y la flexibilidad en sesiones separadas. El objetivo de este estudio fue comparar los efectos individuales y combinados de 6 semanas de estiramiento PNF y entrenamiento pliométrico (PLYOT) en la potencia muscular y la flexibilidad para jugadores de voleibol jóvenes. Treinta y siete jugadores de voleibol jóvenes participaron en el estudio actual. Se distribuyeron en cuatro grupos; PNF $(n=10)$, PLYOT $(n=10)$, Combinando PNF y PLYOT $(C O M B)(n=10)$, y grupo control sin PNF y PLYOT $(\mathrm{CON})(\mathrm{n}=7)$, se probaron antes (PRE) y después (POST) entrenamiento de 6 semanas para potencia muscular [es decir salto vertical (VJ), lanzamiento de balón medicinal sentado (SMTH) y lanzamiento de balón de poder rotativo (RPTH)] y flexibilidad [es decir, prueba de sentarse y estirarse (SRT), prueba de flexibilidad de hombro y muñeca (SWFT) y prueba de rotación del tronco (TRT)]. Los resultados han mostrado efectos significativos del tiempo para todas las variables de estudio $(\mathrm{p} \leq 0.05)$ de todos los grupos excepto que el grupo CON no tuvo efectos significativos $(\mathrm{p}>0.05)$. Hubo diferencias estadísticamente significativas a favor del grupo COMB $(\mathrm{p} \leq 0.05)$ en la evaluación POST en las variables de potencia muscular en comparación con los grupos PNF y PLYOT, mientras que no se encontraron diferencias estadísticamente significativas $(\mathrm{p}>0.05)$ entre PNF, PLYOT y $\mathrm{COMB}$ en todas las variables de flexibilidad. En

\footnotetext{
${ }^{15}$ Department of General Courses, Faculty of Education and Arts, Northern Border University, Saudi Arabia.

${ }^{16}$ Department of Training and Sport Movement Sciences, Faculty of Physical Education, Tanta University, Egypt.
} 
Keywords: Contract-relax method; Muscular strength; Range of motion; Static stretching; Stretch-shortening cycle.

\section{Introduction}

Volleyball is one of the most important team sports widely played and followed worldwide, it requires some physical qualities, as endurance, strength, power, agility, flexibility etc. Developing of these qualities together at the same time represents a challenge for coaches and players, especially in the preparation period when players typically back to training after an off-season in a de-conditioned case. Muscular power and flexibility of the most necessary physical components for the volleyball player and the literature showed that the development of muscle strength increases significantly in the case of increasing joint' range of motion (ROM) (Marques et al., 2009).

Flexibility is the ability of the muscle to stretch, the common manner used for improving flexibility is muscle stretching, that carry out either statically or dynamically (Page, 2012). Muscle stretching is used to enhance performance, reduce injury, developing flexibility and alleviating muscular soreness. Therefore, it is a manner popular used in rehabilitation and training and it is utilized in the warm-up. Three basic kinds of stretching that were applied in flexibility training; static stretching, dynamic stretching, and proprioceptive neuromuscular facilitation (PNF). PNF stretching utilizes static stretching and isometric contractions of the target muscle (TM) in a consecutive style. Static and PNF stretching are preferred to improve flexibility, while dynamic stretching good for warm-up (Costa et al., 2014; D. Medeiros \& Martini, 2017).

PNF is a stretching mechanism used for enhancing muscle plasticity and has an effective impact on ROM. Contract-relax method (CR) one of the most common technique is seen in the literature, The CR method is based on the TM being elongated with a help of the trainer and held in that posture, then the player performes a maximum isometric contraction to the TM for a certin time, followed by the period of relaxation of the TM that generally contains negative prolongation (Hindle, Whitcomb, Briggs, \& conclusión, el efecto combinado de PNF y PLYOT ha superado el efecto individual de ellos sobre la potencia muscular pero no sobre las variables de flexibilidad.

Palabrase claves: Método de contracciónrelajación; Fuerza muscular; Rango de movimiento; Estiramiento estático; Ciclo de estiramientoacortamiento.

Hong, 2012; Kay, Dods, \& Blazevich, 2016). Previously PNF studies have focused on the impact of intervention on given outcome measures, like ROM, peak torque, muscular strength and athletic performance (Konrad, Gad, Tilp, \& Sports, 2015; Papadimitriou, Loupos, Tsalis, Manou, \& Sport, 2017), the results of these studies showed an improvement in the ROM and strength characteristics of the different samples, and PNF was more effective when implemented after training and repeated two times per week minimum to ensure lasting ROM and sustained useful effects. Various studies have compared the effects of using different methods of stretching on ROM and muscular strength (Ayala F., 2015; Minshull, Eston, Bailey, Rees, \& Gleeson, 2014; Sozbir et al, 2016), these studies showed a preference improvement in ROM for PNF and static stretching when compared with dynamic stretching. Some studies investigated the effect of PNF on anaerobic endurance, balance, agility, and speed, the results showed significant effects of PNF in those physical components (Alemdaroglu, Koklu, \& Koz, 2017; Islamoglu, Atan, Unver, \& Cavusoglu, 2017).

PLYOT can reinforce improvements in vertical jump (VJ) performance, speed, lower limb strength, muscle power, and increased joint proprioception. It is rapid an eccentric action followed immediately by a concentric action of the same muscle, that is known as "stretchshortening cycle" (SSC) which links strength with speed of movement. These exercises are intended to reduce the cycle time between the eccentric action, and a concentric action (Miller, Herniman, Ricard, Cheatham, \& Michael, 2006). Prior studies showed improvement in muscular power, Agility, flexibility, sprinting when plyometric exercises have executed (MPTh, MPTh, \& Research, 2016; Negra et al., 2017; Slimani, Chamari, Miarka, Del Vecchio, \& Chéour, 2016).

Several studies have been done to examine the individual effect of PNF stretching and PLYOT 


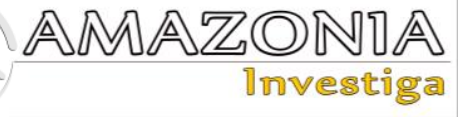

on power and flexibility in different sports and age groups, but no any study investigate the combined effect of PNF stretching and PLYOT, one of study has investigated the acute effects of isolated static stretching or combined with dynamic exercises on strength (Fortier, Lattier, Babault, \& Sports, 2013), another study has investigated the comparative and combined effect of PLYOT and dynamic stretching on VJ (Shaji \& Isha, 2009), combining plyometrics with dynamic stretching has been shown in professional basketball players (Ramachandran \& Pradhan, 2014), and combining of PNF with elastic resistance bands in health females has investigated (Areas et al., 2013). But to date, there does not seem to be any study have been investigated the combined effect of PNF stretching and PLYOT, moreover, it is the first study tried to investigate the combined effect of PNF stretching and PLYOT in Egyptian male young volleyball players. Knowledge gained through this study could help to make PLYOT more effective when PNF stretching added to the workouts without having to isolate strength and flexibility on separate sessions. Thus, young volleyball players could improve their workout without adding time or energy.

So, the purpose of the present study was to compare the individual and combined effects of 6-week of PNF stretching and PLYOT in muscular power and flexibility for male young volleyball players. Authors hypothesized that (1) muscular power and flexibility would increase in all training groups [i.e. PNF group, PLYOT group, and COMB group], (2) COMB group would have more gains in muscular power and flexibility than the other two groups.

\section{Methodology}

\section{Subjects}

Thirty-seven male young volleyball players have participated in the current study. They were distributed in a balanced manner according to their Pre-values of study variables into four groups; PNF $(\mathrm{n}=10)$, PLYOT $(\mathrm{n}=10)$, COMB $(\mathrm{n}=10)$, and a control group without PNF and PLYOT $(\mathrm{CON})(\mathrm{n}=7)$. The inclusion criteria for the participants were healthy, free from any injuries, no use of any ergogenic supplements, not participate in any regular resistance, plyometric and flexibility training during the study, and If participants missed more than one training session, they were removed from the study. The participants' descriptive characteristics have presented in (Table 1). All participants were fully informed about the study and possible risks before giving their written consent to participate. The research project was conducted in accordance with the Declaration of Helsinki for human research. The study was approved by the Deanship of Scientific Research, Northern Border University, Arar, K.S.A. (EAR2017-1-8-F-7521).

Table 1.

Subjects' characteristics.

\begin{tabular}{|c|c|c|c|c|c|c|c|c|c|c|}
\hline \multirow{2}{*}{ Variables } & \multicolumn{2}{|c|}{$\begin{array}{l}\text { PNF } \\
(n=10)\end{array}$} & \multicolumn{2}{|c|}{$\begin{array}{l}\text { PLYOT } \\
(n=10)\end{array}$} & \multicolumn{2}{|c|}{$\begin{array}{l}\text { COMB } \\
(n=10)\end{array}$} & \multicolumn{2}{|c|}{$\begin{array}{l}\text { CON } \\
(n=7)\end{array}$} & \multicolumn{2}{|c|}{$\begin{array}{l}\text { Total } \\
(\mathbf{n}=37)\end{array}$} \\
\hline & Mean & \pm SD & Mean & \pm SD & Mean & \pm SD & Mean & \pm SD & Mean & $\pm \mathrm{SD}$ \\
\hline Age (y) & 16.60 & 0.52 & 16.40 & 0.52 & 16.30 & 0.48 & 16.43 & 0.53 & 16.43 & 0.51 \\
\hline Weight (kg) & 66.40 & 2.32 & 65.50 & 1.48 & 65.60 & 3.27 & 66.43 & 1.99 & 65.98 & 2.36 \\
\hline Height (m) & 1.69 & 0.03 & 1.69 & 0.02 & 1.68 & 0.03 & 1.70 & 0.03 & 1.69 & 0.03 \\
\hline BMI $\left(\mathrm{kg} / \mathrm{m}^{2}\right)$ & 23.32 & 1.02 & 22.93 & 0.49 & 23.29 & 0.74 & 23.99 & 0.59 & 23.18 & 0.20 \\
\hline
\end{tabular}

$\mathrm{PNF}=$ proprioceptive neuromuscular facilitation stretching; $\mathrm{PLYOT}=$ plyometric training; $\mathrm{COMB}=$ Combining PLYOT and PNF; CON= control group without PNF and PLYOT; BMI= body mass index; no significant differences for pretraining characteristics between groups $(p>0.05)$.

\section{Experimental Design}

Study started in June 2019 after the end of the competition period by one week, subjects were tested before (PRE) and after (POST) 6-week training for muscular power [i.e. vertical jump (VJ) (Teo, Newton, Newton, Dempsey, \& Fairchild, 2016), seated medicine ball throw (SMTH), and rotational power ball throw (RPTH) (Algotsson, 2016)] and flexibility [i.e. sit\& reach test (SRT) (Miyamoto, Hirata,
Kimura, \& Miyamoto-Mikami, 2018), shoulder\& wrist flexibility test (SWFT), and trunk rotation test (TRT) (Bullock et al., 2018)].

One week before the start of the experiment, all subjects reported to the Tanta club indoor hall two times in non-consecutive days. On the 1st visit; all subjects were provided with an information sheet setting out details of the experiment, and written informed consent were completed and signed. They changed into sports 
clothes (running shoes, shorts, and t-shirt), body weight and height were recorded using a balance weighing scales and portable stadiometer, respectively. Body mass index (BMI) was calculated using the standard formula [mass $(\mathrm{kg}) /$ height2 (m)]. After warming up, subjects completed a familiarization session, this session familiarized the subjects with the equipment and proper tests technique. Two days after the 1st visit of familiarization session, all subjects tested for muscular power first (i.e. VJ, SMTH, and RPTH) and then flexibility (i.e. SRT, SWFT, and TRT) as a PRE- evaluation. Before the test, subjects performed a warm-up which included 5 min of light running and $5 \mathrm{~min}$ dynamic stretching exercises. All testing sessions for 4 groups used the same test order, equipment, warm-up, and time of the tests (between 5:00 and 8:00 PM). The POST-evaluation was performed for each group after $48 \mathrm{hrs}$ from the last session in the 6-week training. All testing and training sessions were performed at Tanta club indoor hall and supervised by the same authors.

\section{Plyometric training program}

PLYOT program was designed based on previous studies (Manouras, Papanikolaou, Karatrantou, Kouvarakis, \& Gerodimos, 2016; Patil, 2016; Shaji \& Isha, 2009). It was divided into three mesocycles of two weeks each. The training load was progressively increased biweekly. A more detailed description of the progression of the PLYOT program is presented in (Table 2). Subjects of PLYOT and COMB groups took part in a PLYOT program, 3 days/ week for 6 weeks included 10 explosive power and force production exercises for upper limb, lower limb, and core muscles. The PLYOT group trained on Saturday, Monday, and Wednesday, whereas the COMB group trained on Sunday, Tuesday, and Thursday. The training sessions consist of a warm-up, a plyometric exercise, and a cool-down period (10 $\mathrm{min}, 30-45$, and $5 \mathrm{~min}$; respectively). The warm-up and cool-down periods included stretching exercises and light running.

Table 2.

Plyometric training and PNF stretching program for PLYOT and COMB groups.

\begin{tabular}{|c|c|c|c|c|}
\hline \multicolumn{2}{|c|}{ Cycles } & Mesocycle 1 & Mesocycle 2 & Mesocycle 3 \\
\hline \multicolumn{2}{|c|}{ Duration of the cycle (week) } & 2 & 2 & 2 \\
\hline \multicolumn{2}{|c|}{ Weeks } & $1 \& 2$ & $3 \& 4$ & $5 \& 6$ \\
\hline \multirow{7}{*}{ 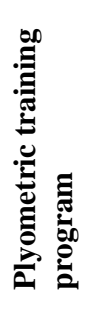 } & Box height (cm) & 50 & 55 & 60 \\
\hline & MB weight (kg)* & 2 & 2 & 3 \\
\hline & Repetitions & 10 & 12 & 15 \\
\hline & Number of sets & 2 & 3 & 4 \\
\hline & Rest intervals (min) & 2 & 2 & 3 \\
\hline & Number of exercises & \multicolumn{3}{|c|}{$\begin{array}{l}10 \text { (i.e. Jumping lunges, Knee tuck jump, Box jump, Lateral shuffle, } \\
\text { Dynamic step ups, Depth jump, MB chest pass, seated MB trunk } \\
\text { rotation, MB overhead throw, MB underhand throw) }\end{array}$} \\
\hline & Intensity (ROM) & Full & Full & Full \\
\hline \multirow{5}{*}{ 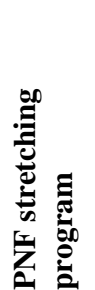 } & Stretch duration (sec) & 10 & 12 & 15 \\
\hline & Contraction duration (sec) & 4 & 5 & 6 \\
\hline & Relax duration (sec) & 10 & 12 & 15 \\
\hline & Number of repetitions* & 3 & 4 & 5 \\
\hline & Number of exercises & \multicolumn{3}{|c|}{$\begin{array}{l}8 \text { (i.e. Supine hamstring stretch, laying quadriceps stretch, supine } \\
\text { gluteus stretch, seated gastrocnemius stretch, supine spinal rotation } \\
\text { stretch, seated upper trapezius stretch, seated chest stretch, seated } \\
\text { triceps stretch). }\end{array}$} \\
\hline
\end{tabular}

\section{PNF stretching training program}

PNF stretching training program was designed according to the published previous studies (Frederick \& Frederick, 2017; Hindle et al., 2012; McAtee, 2013; D. Medeiros \& Martini, 2017; D. M. Medeiros, Cini, Sbruzzi, Lima, \& practice, 2016). It was divided into three mesocycles of two weeks each. The stretching intensity was self-determined by a subject' full ROM but set to the threshold of moderate discomfort, not pain. Each stretching exercise was achieved on the right and left limb before another exercise was performed, without a rest interval between limbs. The training load was progressively increased biweekly. A more detailed description of the progression of the PNF stretching program is presented in (Table 2). Subjects of PNF and COMB groups took part in a PNF stretching training program using CR technique, 3 days/ week for 6 weeks including 8 PNF stretching exercises for upper limb, lower 


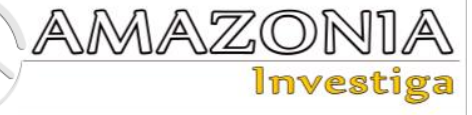

limb, and core muscles. The PNF group trained on Saturday, Monday, and Wednesday, whereas the COMB group trained on Sunday, Tuesday, and Thursday. The PNF stretching training was performed after PLYOT for COMB group.

\section{Statistical analysis}

Data are presented as mean and standard deviations $( \pm \mathrm{SD})$. The statistical calculations were performed using STATISTICA software version 10 (StatSoft, Tulsa, OK, USA). All variables have had a normal distribution and homoscedasticity. The repeated-measures analysis of variation (ANOVA) (4 models by 2 time points) was used to check the significant differences between groups, and when statistical significance $(\mathrm{P} \leq 0.05)$ was found, the Tukey post-hoc test for comparisons was applied to compare the difference between groups in PRE, and POST time points. a paired sample t-test was used to check the significant differences between PRE, and POST variables for each group.

\section{Results and discussion}

The purpose of the present study was to compare the individual and combined effect of PNF stretching and PLYOT in muscular power and flexibility among volleyball players in three experimental groups, the $1^{\text {st }}$ underwent to the PNF stretching program only, and the $2^{\text {nd }}$ group underwent to PLYOT program only to identify the individual effect of each in muscular power and flexibility. The $3^{\text {rd }}$ group underwent to both PNF stretching and PLYOT programs to identify the combined effect of them in muscular power and flexibility. A control group used to identify the effect of the three conditions in both muscular power and flexibility variables.

There were no differences between the four groups in the PRE- test for all study variables ( $p$ $>0.05)$. All subjects of PNF, PLYOT, and
COMB groups completed the 6-week training with attendance rate more than $95 \%$, with only 5 participants absent for 1 training session $(\mathrm{PNF}=$ 2 players; PLYOT $=1$ player; $\mathrm{COMB}=2$ players) during the 6 -week training programs.

The results have demonstrated that all experimental groups (i.e. PNF, PLYOT, and COMB) have a significant increase in muscular power variables (i.e. VJ, SMTH, and RPTH), and flexibility variables (i.e. SRT, SWFT, and TRT) at POST-evaluation for volleyball players, compared with PRE- evaluation and compared with CON group that have not significant effect over the time, thus the $1^{\text {st }}$ hypothesis was accepted (Table3).

The results also have showed that COMB group has a significant difference in muscular power variables but has not a significant difference in flexibility variables compared with PNF and PLYOT groups, as well no significant differences in muscular power and flexibility variables between PNF and PLYOT groups. So, the $2^{\text {nd }}$ hypothesis was accepted in muscular power but not accepted for flexibility (Table3).

\section{Muscular power}

The study has shown statistically significant differences favor COMB group $(p \leq 0.05)$ at the POST evaluation in VJ, SMTH, and RPTH (26.3\%, 18,77\%, and $17.53 \%$; respectively) in comparison with the PNF group $(13.95 \%, 7.03 \%$, and $6.9 \%$; respectively), and in comparison, with the PLYOT group $(16.1 \%, 15,41 \%$, and $15.27 \%$; respectively). Also, results have shown no statistically significant differences $(p>0.05)$ between PNF and PLYOT groups in VJ, SMTH, and RPTH at POST evaluation, however, the PLYOT group shown a higher percentage increase in muscular power than PNF group for those exercises (Table 3) (Fig. 1). 
Table 3.

Pre- and post-testing data for each variable.

\begin{tabular}{|c|c|c|c|c|c|}
\hline \multirow{2}{*}{ Variable } & \multirow{2}{*}{ Group } & \multicolumn{2}{|l|}{ PRE } & \multicolumn{2}{|l|}{ POST } \\
\hline & & Mean & \pm SD & Mean & \pm SD \\
\hline \multirow{4}{*}{$\mathrm{VJ}(\mathbf{c m})$} & PNF & 49 & 2.37 & $55.83 * \#$ & 2.56 \\
\hline & PLYOT & 48.67 & 1.75 & $56.50 * \#$ & 1.38 \\
\hline & COMB & 48.17 & 2.99 & $60.83^{* \# \boldsymbol{\&} \$}$ & 2.14 \\
\hline & $\mathrm{CON}$ & 50 & 3.54 & 51.63 & 3.16 \\
\hline \multirow{4}{*}{ SMTH (m) } & PNF & 4.45 & 0.26 & $4.78 * \#$ & 0.27 \\
\hline & PLYOT & 4.65 & 0.34 & $5.37 * \#$ & 0.31 \\
\hline & COMB & 4.62 & 0.43 & $5.48 * \# \boldsymbol{\&} \$$ & 0.44 \\
\hline & $\mathrm{CON}$ & 4.64 & 0.47 & 4.66 & 0.44 \\
\hline \multirow{4}{*}{ RPTH (m) } & PNF & 9.42 & 0.53 & $10.07 * \#$ & 0.54 \\
\hline & PLYOT & 9.72 & 0.78 & $11.20 * \#$ & 0.86 \\
\hline & СOMB & 9.60 & 1.02 & $11.28 * \# \boldsymbol{\&} \$$ & 0.90 \\
\hline & $\mathrm{CON}$ & 9.48 & 1.24 & 9.50 & 1.23 \\
\hline \multirow{4}{*}{ SRT (cm) } & PNF & 7.83 & 1.60 & $14.83 * \#$ & 3.54 \\
\hline & PLYOT & 7.67 & 3.78 & $9.83 * \#$ & 3.87 \\
\hline & COMB & 7.83 & 3.43 & $14.66 * \#$ & 4.23 \\
\hline & ASBS & 7 & 3.16 & 7.20 & 3.35 \\
\hline \multirow{4}{*}{ SWFT (cm) } & PNF & 9.97 & 1.15 & $14 * \#$ & 0.89 \\
\hline & PLYOT & 10.30 & 1.69 & $11.50 * \#$ & 1.38 \\
\hline & COMB & 10.58 & 1.64 & $14.67 * \#$ & 1.08 \\
\hline & $\mathrm{CON}$ & 10.76 & 1.72 & 10.82 & 1.73 \\
\hline \multirow{4}{*}{ TRT (cm) } & PNF & 9.67 & 2.42 & $15 * \#$ & 2.53 \\
\hline & PLYOT & 10.17 & 3.43 & $11.50 * \#$ & 3.02 \\
\hline & COMB & 10.67 & 3.14 & $16 * \#$ & 2 \\
\hline & $\mathrm{CON}$ & 10.20 & 3.19 & 10.60 & 2.97 \\
\hline
\end{tabular}

Values were expressed by mean $\pm \mathrm{SD}(\mathrm{n} ; \mathrm{PNF}=6, \mathrm{PLYOT}=6, \mathrm{COMB}=6, \mathrm{CON}=5)$, VJ= vertical jump; $\mathrm{SMTH}=$ seated medicine ball throw; RPTH = rotational Powerball throw; SRT $=$ sit and reach test; SWFT= shoulder and wrist flexibility test; TRT $=$ trunk rotation test; ${ }^{*}$ statistically significant difference $(\mathrm{p} \leq 0.05)$ in comparison with PRE; \# statistically significant difference $(p \leq 0.05)$ in comparison with CON; \& statistically significant difference $(p \leq 0.05)$ in comparison with PNF; \$ statistically significant difference in comparison with PLYOT.

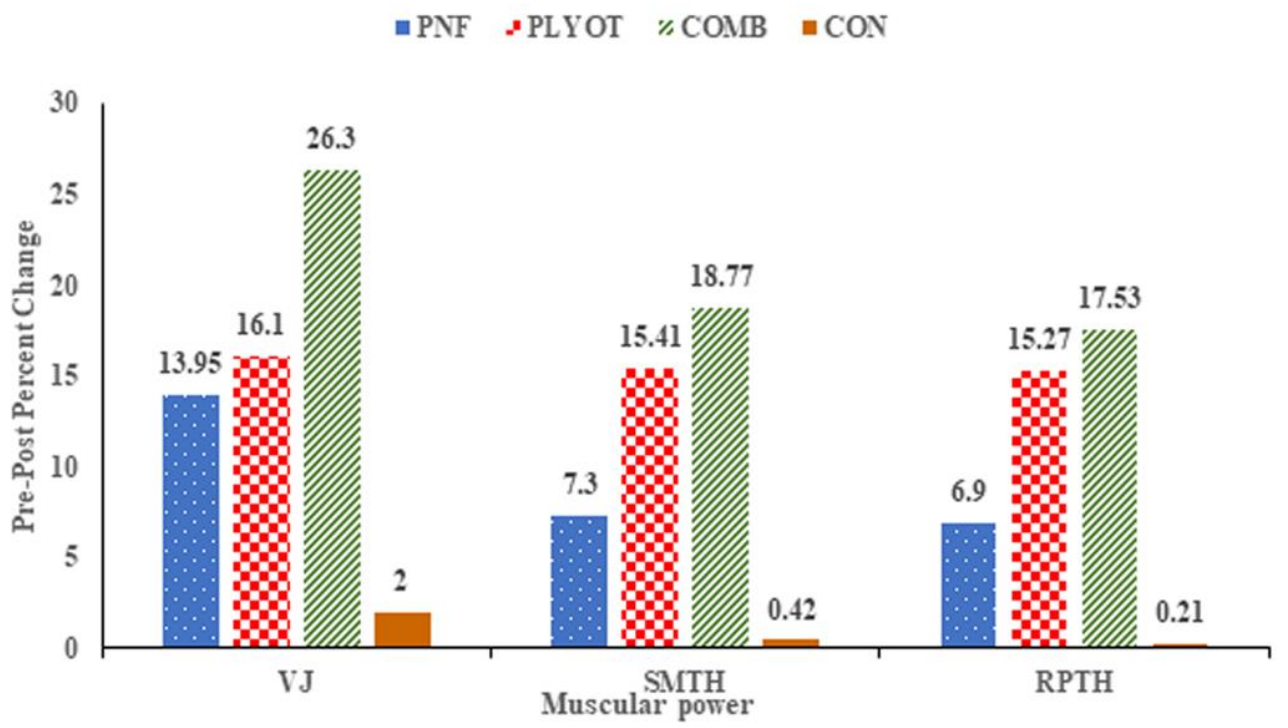

Fig 1. Rate of changes in muscular power variables for all groups, $\mathrm{PNF}=$ proprioceptive neuromuscular facilitation stretching; PLYOT= plyometric training; $\mathrm{COMB}=\mathrm{Combining}$ PLYOT and PNF; $\mathrm{CON}=$ control group without PNF and PLYOT; VJ= vertical jump; SMTH= seated medicine ball throw. 


\section{AMAZONIA
1mvestiga}

All muscular power variables (i.e. VJ, SMTH, and RPTH) were improved in PNF group which underwent 6-week of PNF stretching program and were improved in PLYOT group which underwent 6-week of PLYOT program, while COMB group which underwent 6-week of PNF stretching program and PLYOT program showed the best improvement in muscular power variables.

The improvement in muscular power variables of PNF group might attribute to the increased muscle length because of PNF stretching program (D. Medeiros \& Martini, 2017; D. M. Medeiros et al., 2016). These findings are consistent with study of (Nelson, Chambers, McGown, Penrose, \& Therapy, 1986) that showed PNF stretching has a similar effect of weight training in improving muscular strength, VJ and throwing distance in untrained females after 8 weeks of PNF stretching program, study conducted by (Shaji \& Isha, 2009) who observed the acute effect of stretching on vertical jump of basketball players after 4 weeks of dynamic stretching program, and study of (Akbulut \& Agopyan, 2015) that showed improvement in young soccer kick performance in terms of ball speed after PNF stretching program for 8-week. The improvement in muscular power variables of PLYOT group imputes to neural adaptation for the nervous system (i.e. increasing the degree of muscle coordination, elasticity of muscles and Golgi tendon organs, and increasing recruitment of motor units) resulting from PLYOT program (Maffiuletti et al., 2002; Manouras et al., 2016). The SSC inducing stretch reflex and let maximum energy transfer between elongation and contractions phases. The stored elastic energy within the muscle is used to produce more force than can be supplied by a concentric action separately (Miller et al.,
2006). These findings are consistent with many studies that indicated significant improvements in VJ following PLYOT program for 6-8 weeks (Manouras et al., 2016; Santos, Janeira, \& Research, 2011). The improvement in muscular power variables of COMB group attribute to the combined effects of PNF and PLYOT on condition the PNF stretching completed after PLYOT to induce increase in muscular power and athletic performance (Caplan, Rogers, Parr, Hayes, \& Research, 2009; Nelson, Kokkonen, Arnall, \& Research, 2005), a previous studies has proofed that the merging of strength and flexibility training reduce muscle-tendon unit (MTU) hysteresis more than strength training Singularly, hysteresis is the energy lost as heat during extension of viscoelastic substances (Kubo \& Science, 2005). These findings are consistent with the study of (Ramachandran \& Pradhan, 2014) who observed the statistically significant increase in vertical jump height in trained basketball players after 2-week of combining PLYOT and stretching.

\section{Flexibility}

There were statistically significant differences between PNF, PLYOT, and COMB groups ( $p>$ $0.05)$ at the POST evaluation in SRT, SWFT, and TRT. However, the PNF group shown a higher percentage increase in flexibility $(89.36 \%, 40.47 \%$, and $55.17 \%$; respectively) than COMB group $(87.23 \%, 38.58 \%$, and $50 \%$; respectively) and PLYOT group $(28.26 \%, 11.65 \%$, and $13.11 \%$; respectively) for those exercises, however the PNF group shown a higher percentage increase in muscular power than COMP and PLYOT groups for those exercises (Table 3) (Fig. 2).

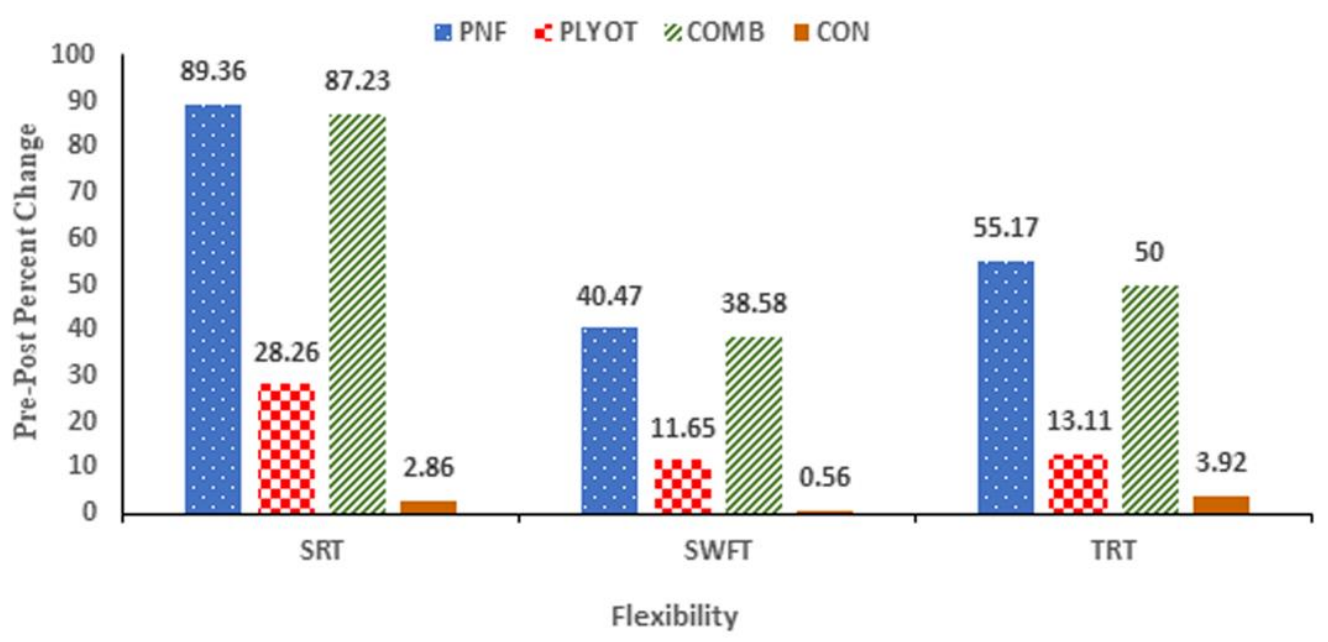

Fig 2. Rate of changes in flexibility variables for all groups, $P N F=$ proprioceptive neuromuscular facilitation stretching; PLYOT= plyometric training; COMB=Combining PLYOT and PNF; CON= control group without PNF and PLYOT; RPTH = rotational Powerball throw; $S R T=$ sit and reach test; $S W F T=$ shoulder and wrist flexibility test; $T R T=$ trunk rotation test. 
All flexibility variables (i.e. SRT, SWFT, and TRT) were improved in PLYOT group which underwent 6-week of PLYOT program and were improved in COMB group which underwent 6week of PNF stretching program and PLYOT program, while PNF group which underwent 6week of PNF stretching program showed the best improvement in flexibility variables.

The improvement in flexibility variables of PNF group after the PNF stretching program might attribute to one or more of three main choices used to clarify the increasing of muscle length (1) sarcomerogenesis (Zöllner, Abilez, Böl, \& Kuhl, 2012), (2) boost in stretching tolerance (increase in passive torque at end ROM) (Konrad et al., 2015), and (3) reduction in MTU hardness (Guissard, Duchateau, \& Medicine, 2004). These findings are consistent with many studies that PNF stretching using any methods lead to increase ROM and flexibility when PNF methods were performed after exercising (Minshull et al., 2014). The improvement in flexibility variables of PLYOT group attribute to the increase in excitability of neuromuscular receptors of muscles, tendons, ligaments, and joints (Jaffre et al., 2001). These findings are consistent with some of the studies that observed the statistically significant improvements in flexibility in female dancer and gymnasts after 6-month of PLYOT (McGilvray, Haslam, \& Sport, 1999; Patil, 2016). The improvement in flexibility variables of COMB group attribute to the combined effects of PNF and PLYOT on condition the PNF stretching completed after PLYOT to induce an increase in ROM and flexibility (Caplan et al., 2009; Nelson et al., 2005).

\section{Conclusions}

Through the study sample, our findings indicate that the combined effect of PNF and PLYOT has surpassed the individual effect of them on muscular power but not on flexibility variables, the study showed that the improvement rates of flexibility higher than muscular power for all experimental groups, and the improvement rates of COMB were ranked first followed by PLYOT and finally PNF in muscular power variables, while the improvement rates of PNF was ranked first followed by COMB and finally PLYOT in flexibility variables.

\section{Acknowledgments}

The authors thank all the participants for their time and effort, and Mark Halaki for his help with data statistical analysis. This study was approved and supported by the grant no. EAR-2017-1-8-F-
7521 from the Deanship of Scientific Research, Northern Border University, Arar, K.S.A.

\section{References}

Akbulut, T., \& Agopyan, A. (2015). Effects of an Eight-Week Proprioceptive Neuromuscular Facilitation Stretching Program on Kicking Speed and Range of Motion in Young Male Soccer Players. J Strength Cond Res, 29(12), 3412-3423.

Alemdaroglu, U., Koklu, Y., \& Koz, M. (2017). The acute effect of different stretching methods on sprint performance in taekwondo practitioners. J Sports Med Phys Fitness, 57(9), 1104-1110.

Algotsson, M. (2016). Construct validity and test-retest reliability of a rotational maximum strength test and rotational power test in 1080 Quantum. (Dissertation). Retrieved from http://urn.kb.se/resolve?urn=urn:nbn:se:hh:diva31060.

Areas, G., Borghi-Silva, A., Lobato, A. N., Silva, A. A., Freire Jr, R. C., \& Areas, F. Z. J. B. j. o. p. t. (2013). Effect of upper extremity proprioceptive neuromuscular facilitation combined with elastic resistance bands on respiratory muscle strength: a randomized controlled trial. Braz J Phys Ther, 17(6), 541546.

Ayala F., C. M. D. S., de Baranda P.S., Santonja F. (2015). Acute effects of two different stretching techniques on isokinetic strength and power. J Revista Andaluza de Medicina del Deporte, 8(3), 93-102.

Bullock, G. S., Schmitt, A. C., Chasse, P. M., Little, B. A., Diehl, L. H., \& Butler, R. J. (2018). The relationship between trunk rotation, upper quarter dynamic stability, and pitch velocity. The Journal of Strength \& Conditioning Research, 32(1), 261-266.

Caplan, N., Rogers, R., Parr, M. K., Hayes, P. R. J. T. J. o. S., \& Research, C. (2009). The effect of proprioceptive neuromuscular facilitation and static stretch training on running mechanics. J Strength Cond Res, 23(4), 1175-1180.

Costa, P. B., Herda, T. J., Herda, A. A., Cramer, J. T. J. M., Sports, S. i., \& Exercise. (2014). Effects of dynamic stretching on strength, muscle imbalance, and muscle activation. Med Sci Sports Exerc, 46(3), 586-593.

Fortier, J., Lattier, G., Babault, N. J. S., \& Sports. (2013). Acute effects of short-duration isolated static stretching or combined with dynamic exercises on strength, jump and sprint performance. 28(5), e111-e117.

Frederick, A., \& Frederick, C. (2017). Stretch to win. Human Kinetics. 


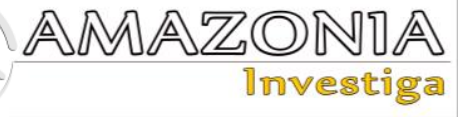

Guissard, N., Duchateau, J. J. M., \& Medicine, N. O. J. o. t. A. A. o. E. (2004). Effect of static stretch training on neural and mechanical properties of the human plantar-flexor muscles. 29(2), 248-255.

Hindle, K., Whitcomb, T., Briggs, W., \& Hong, J. (2012). Proprioceptive neuromuscular facilitation (PNF): Its mechanisms and effects on range of motion and muscular function. Journal of human kinetics, 31(2012), 105-113.

Islamoglu, I., Atan, T., Unver, S., \& Cavusoglu, G. (2017). Effects of Different Durations of Static Stretching on Flexibility, Jumping, Speed and Agility Performance. The Anthropologist, 23(3), 454-461.

Jaffre, C., Courteix, D., Dine, G., Lac, G., Delamarche, P., Benhamou, L. J. J. o. P. E., \& Metabolism. (2001). High-impact loading training induces bone hyperresorption activity in young elite female gymnasts. J Pediatr Endocrinol Metab, 14(1), 75-84.

Kay, A. D., Dods, S., \& Blazevich, A. J. (2016). Acute effects of contract-relax (CR) stretch versus a modified $\mathrm{CR}$ technique. European journal of applied physiology, 116(3), 611-621. Konrad, A., Gad, M., Tilp, M. J. S. J. o. M., \& Sports, S. i. (2015). Effect of PNF stretching training on the properties of human muscle and tendon structures. Scand J Med Sci Sports, 25(3), 346-355.

Kubo, K. J. I. J. o. S., \& Science, H. (2005). In vivo elastic properties of human tendon structures in lower limb. 3(Special_Issue_2005), 143-151.

Maffiuletti, N. A., Dugnani, S., Folz, M., Di Pierno, E., Mauro, F. J. M., Sports, S. i., \& Exercise. (2002). Effect of combined electrostimulation and plyometric training on vertical jump height. Med Sci Sports Exerc, 34(10), 1638-1644.

Manouras, N., Papanikolaou, Z., Karatrantou, K., Kouvarakis, P., \& Gerodimos, V. (2016). The efficacy of vertical vs. horizontal plyometric training on speed, jumping performance and agility in soccer players. International Journal of Sports Science \& Coaching, 11(5), 702-709.

Marques, M. C., Van den Tillaar, R., Gabbett, T. J., Reis, V. M., González-Badillo, J. J. J. T. J. o. S., \& Research, C. (2009). Physical fitness qualities of professional volleyball players: determination of positional differences. J Strength Cond Res, 23(4), 1106-1111.

McAtee, R. E. (2013). Facilitated stretching. Human kinetics.

McGilvray, J. A., Haslam, R. J. R. Q. f. E., \& Sport. (1999). The effects of resistance and plyometric training on the vertical jump and flexibility performance of female dancers.
Research Quarterly for Exercise and Sport, 70 (Supplement 1), A17.

Medeiros, D., \& Martini, T. J. A. C. C. J. Y. P. T. (2017). Does Stretching Have Long-Term Effects on Muscle Performance. 7(269), 2.

Medeiros, D. M., Cini, A., Sbruzzi, G., Lima, C. S. J. P. t., \& practice. (2016). Influence of static stretching on hamstring flexibility in healthy young adults: Systematic review and metaanalysis. Physiother Theory Pract, 32(6), 438445.

Miller, M. G., Herniman, J. J., Ricard, M. D., Cheatham, C. C., \& Michael, T. J. (2006). The effects of a 6-week plyometric training program on agility. J Sports Sci Med, 5(3), 459-465.

Minshull, C., Eston, R., Bailey, A., Rees, D., \& Gleeson, N. J. E. j. o. s. s. (2014). The differential effects of PNF versus passive stretch conditioning on neuromuscular performance. Eur J Sport Sci, 14(3), 233-241.

Miyamoto, N., Hirata, K., Kimura, N., \& Miyamoto-Mikami, E. (2018). Contributions of hamstring stiffness to straight-leg-raise and sitand-reach test scores. International journal of sports medicine, 39(02), 110-114.

MPTh, R. G., MPTh, S. P. P. J. I. J. o. T., \& Research, R. (2016). Plyometric training effect on fexibility in female pubertal gymnasts. 5(1), 37.

Negra, Y., Chaabene, H., Sammoud, S., Bouguezzi, R., Abbes, M. A., Hachana, Y., \& Granacher, U. (2017). Effects of plyometric training on physical fitness in prepuberal soccer athletes. International Journal of Sports Medicine, 38(05), 370-377.

Nelson, A. G., Chambers, R. S., McGown, C. M., Penrose, K. W. J. J. o. O., \& Therapy, S. P. (1986). Proprioceptive neuromuscular facilitation versus weight training for enhancement of muscular strength and athletic performance. J Orthop Sports Phys Ther, 7(5), 250-253.

Nelson, A. G., Kokkonen, J., Arnall, D. A. J. T. J. o. S., \& Research, C. (2005). Acute muscle stretching inhibits muscle strength endurance performance. J Strength Cond Res, 19(2), 338343.

Page, P. J. I. j. o. s. p. t. (2012). Current concepts in muscle stretching for exercise and rehabilitation. Int J Sports Phys Ther, 7(1), 109. Papadimitriou, K., Loupos, D., Tsalis, G., Manou, B. J. J. o. P. E., \& Sport. (2017). Effects of proprioceptive neuromuscular facilitation (PNF) on swimmers leg mobility and performance. 17(2), 663.

Patil, R. (2016). Plyometric Training Effect on Flexibility in Female Pubertal Gymnasts. International Journal of Therapies and Rehabilitation Research, 5(1), 37-45. 
Ramachandran, S., \& Pradhan, B. J. I. J. P. P. (2014). Effects of short-term two weeks low intensity plyometrics combined with dynamic stretching training in improving vertical jump height and agility on trained basketball players. Indian J Physiol Pharmacol, 58(2), 133-136.

Santos, E. J., Janeira, M. A. J. T. J. o. S., \& Research, C. (2011). The effects of plyometric training followed by detraining and reduced training periods on explosive strength in adolescent male basketball players. J Strength Cond Res, 25(2), 441-452.

Shaji, J., \& Isha, S. J. A. A. e. J. M. S. (2009). Comparative analysis of plyometric training program and dynamic stretching on vertical jump and agility in male collegiate basketball player. 2(1), 36-46.

Slimani, M., Chamari, K., Miarka, B., Del Vecchio, F. B., \& Chéour, F. (2016). Effects of plyometric training on physical fitness in team sport athletes: a systematic review. Journal of human kinetics, 53(1), 231-247.

Sozbir, K., Willems, Mark E. T., TiryakiSonmez, Gul and Ragauska, P. (2016). Acute effects of contract-relax PNF and static stretching on flexibility, jump performance and EMG activities: A case study. Biology of Exercise, 12(1), 33-55.

Teo, S. Y., Newton, M. J., Newton, R. U., Dempsey, A. R., \& Fairchild, T. J. (2016). Comparing the effectiveness of a short-term vertical jump vs. weightlifting program on athletic power development. Journal of strength and conditioning research, 30(10), 2741-2748. Zöllner, A. M., Abilez, O. J., Böl, M., \& Kuhl, E. J. P. o. (2012). Stretching skeletal muscle: chronic muscle lengthening through sarcomerogenesis. 7(10). 